Mini Review

\title{
IMMUNOLOGICAL ASPECTS OF COGNITIVE FUNCTIONING: HIGHLIGHTS ON THE ROLE OF THE CYTOKINES
}

\author{
A. Trenova ${ }^{1}$, G. Slavov ${ }^{1}$ L. Miteva ${ }^{2}$, M. Manova ${ }^{1}$, S. Stanilova ${ }^{2}$ \\ ${ }^{1}$ Department of Neurology, Faculty of Medicine, Medical University of Plovdiv, Plovdiv, Bulgaria \\ ${ }^{2}$ Department of Molecular Biology, Immunology and Medical Genetics, Medical Faculty, \\ Trakia University, Stara Zagora, Bulgaria
}

\begin{abstract}
The complex interactions between the central nervous system (CNS) and the immune system in normal and pathological conditions have long been a subject of investigations, and a large amount of data have been accumulated in this field. The immune system communicates with the CNS mainly via synthesis and secretion of cytokines. Receptors for cytokines are expressed on cells of hippocampus, which is responsible for the memory functions. Changes in cytokine profile are registered in patients with neurodegenerative dementia of Alzheimer type and increased production of pro-inflammatory cytokines in systemic inflammatory diseases is associated with typical neuropsychological and behavioral signs in experimental and clinical conditions. These and many other evidence confirm the role of the cytokines and immune system respectively in modulation of cognitive functions but the precise mechanisms and targets of their action in normal status and in various diseases are still not fully clarified. This review aims to summarize the discovered effects and consequences of immune-CNS interactions in the field of cognitive functioning and to outline the missing gaps and perspectives for future investigations.
\end{abstract}

Key words: cognition, immune system, cytokines, central nervous system

The nervous and the immune systems are the main regulators, monitoring and maintaining the homeostasis of the organism. Together they provide control and adaptation to changes in the internal and external environment to maintain the integrity and balance of the body. Thus the two systems are in constant interactions to each other. There are resident immune cells in the nervous system (microglia) and peripheral nerve terminals penetrate the immune organs. Nerve cells use immune components such as cytokines and chemokines for sending signals to other cells and the immune cells express receptors for neurotransmitters and poses the ability to synthesize neurotransmitter molecules, such as acetylcholine, glutamate, dopamine, serotonin (1). The immune system plays important role in neurogenesis and neural plasticityprocesses with crucial effect on the cognitive abilities. Important structures in the central

\footnotetext{
*Correspondence to: Anastasiya G. Trenova, Department of Neurology, Faculty of medicine, Medical University of Plovdiv, Bulgaria; Address: 15 a "Vasil Aprilov" Blvd., Plovdiv 4000, Bulgaria, tel./fax: +35932602 205, e-mail:

atrenova@yahoo.com
}

nervous system (CNS) involved in cognitive functioning express receptors for different cytokines.

\footnotetext{
Experimental evidence for influence of the immune system on cognition

Circulating immune cells and especially $\mathrm{T}$ lymphocytes are necessary for maintaining the normal cognitive functioning. Evidence for this are the experimental studies on mice with severe combined immune deficiency (SCID) and nude mice (with selective deficit of mature $\mathrm{T}$ lymphocytes), which show extensive impairment of the memory and learning abilities, connected to the hippocampal activity. Introduction of $\mathrm{T}$ lymphocytes from the wild type in these animals significantly improves the results of memory and learning tests (2-4). In agreement with these data, but difficult to interpret from a clinical point of view are the findings of in transgenic mice with excessive production of monospecific autoreactive $\mathrm{T}$ lymphocytes, directed towards a brain antigen. Experimental animals show better abilities for learning and memory compared to the control group (5).
} 
In adult mice, effects on $\mathrm{T}$ cell immunity, such as bone marrow transplantation after radiation exposure lead to a partial recovery of impaired spatial memory in experimental animals (3). Procedures, such as physical exercises and low-caloric diet, which delay brain aging and related memory impairment, are associated with enhancement of $\mathrm{T}$ cell immunity (6).

Except of microglia cells, which are inherent for the nerve tissue and possess immune functions, meninges with their $\mathrm{T}$ lymphocytes are important place for immune responses. Performance of cognitive tasks leads to migration of $\mathrm{T}$ cells into the meningeal spaces, where they are activated acquiring Th2 phenotype. $\mathrm{T}$ lymphocyte depletion in the meninges causes memory and learning impairment and is accompanied by a transformation of meningeal myeloid cells in those of pro-inflammatory type (7). These data raise the question about the role of proinflammatory and anti-inflammatory mechanisms in the implementation of the cognitive processes.

In basic conditions, i.e. in absence of infectious or other strong pathogenic stimulus, both proinflammatory (IL-1, IL-6, TNF-alpha, IFNgamma) and anti-inflammatory (IL-4, IL-10) cytokines act as regulators of the normal cognitive functioning.

Experimental studies proved the role of IL-1 in synaptic plasticity. Secretion of this cytokine is induced within the hippocampus during the learning process. Studies with knocked out mice have shown that IL-1 is required for the consolidation of memory which depends on proper functioning of the hippocampus. Exogenous administration of low doses of IL-1 can improve hippocampal-dependent memory functioning. Blockade of IL-1 signaling, either by pharmacological or by genetic manipulations impairs memory and learning processes. Excessively elevated levels of IL-1 also have detrimental effect on hippocampal memory functioning, whereas the performance of hippocampal-independent tasks is spared (8). All these evidences suggest the conclusion that low, "physiological" levels of IL-1 in the hippocampus play an important role in normal learning and memory processes.

The role of IL-6 in memory is also quite complex. IL-6 influences learning and memory in different, and even opposite ways under various conditions. IL-6 has been shown to be a regulator of neurogenesis. Neurogenesis is important for cognitive function and modulating memory functions, such as, memory consolidation and some types of
TRENOVA A., et al. hippocampal-dependent learning (9). IL-6 also appears to influence synaptic plasticity as it was shown by number of authors (10-12). Impaired IL-6 signaling is associated with memory improvement (13). Studies of Heyser et al., 1997, and Tha et al., 2000, has demonstrated the role of this cytokine in agerelated cognitive dysfunctions. On the other side, acute administration of IL-6 does not produce any effect on memory, and elevated levels of IL-6 have been associated with protection from memory loss in several medical conditions $(14,15)$. According to the current knowledge, the role of IL-6 in memory depends on the specific conditions under which it is elevated, as well as on the magnitude and duration (acute or chronic) of the elevation (16).

Interleukin-18 (IL-18) is a member of the IL-1 pro-inflammatory cytokine family. It is closely related to IL-1beta, and was detected in the cortex, cerebellum, hippocampus, hypothalamus and striatum. Like IL-1beta, IL18 was shown to inhibit Long Term Potentiation (LTP, used as a cellular model of learning and memory) especially in the rat dentate gyrus (17). These findings suggest that over-expression of IL-18 may has detrimental effect on synaptic plasticity and memory formation.

There are experimental data for the role of another pro-inflammatory cytokine, IFNgamma, in enhancement of neurogenesis. Baron et al. 2008, demonstrated that low amounts of IFN-gamma stimulates neurogenesis in the dentate gyrus of adult mice and improves the spatial learning and memory performance of the animals (18).

Physiological levels of TNF-alpha, in mice, under immunologically non-challenged conditions are essential for normal functioning of memory and learning (19). Previous studies with transgenic mice demonstrated that overexpression of TNF-alpha resulted in altered learning and memory process $(20,21)$. Contradictory to some degree are the results from studies with TNF knocked-out mice, showing no memory impairment or even less susceptibility to the memory impairment caused by brain injury $(22,23)$. There are some evidences that the detrimental effect of TNFalpha on memory and learning is dose and age dependent.

The effects of IL-2 on cognitive functions are not fully clarified yet. Chronic administration of IL-2 has been associated with hippocampal neurodegeneration in rats and suppression of 
long-term potentiation, leading to impaired memory performance. The cytokine also serves as neuroregulatory molecule, promoting neuronal survival, olygodendrocyte proliferation and maturation (24).

The role of the anti-inflammatory cytokines in cognitive functioning seems to be poorly studied. IL-4 - a typical representative of Th-2 cytokines was determined to have an important role in higher brain functions. Mice that lack IL-4 demonstrate cognitive impairment in spatial learning tasks, and this effect can be reversed by transplantation of IL4-competent bone marrow (7). Several experiments suggest a potential role for IL-4 in countering age-related pro-inflammatory changes (25). The cognitive impairment seen in aged mice might be partially explained by the increase in pro-inflammatory cytokines and a decrease in the amount of and sensitivity to the opposing IL-4, through disruption of LTP.

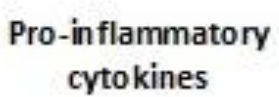

\begin{tabular}{lc} 
TNF-alpha, & IL-4 \\
IL-1, IL-2 \\
IL-6, IL-17 & IL-10 \\
IL-18 & \\
\hline
\end{tabular}

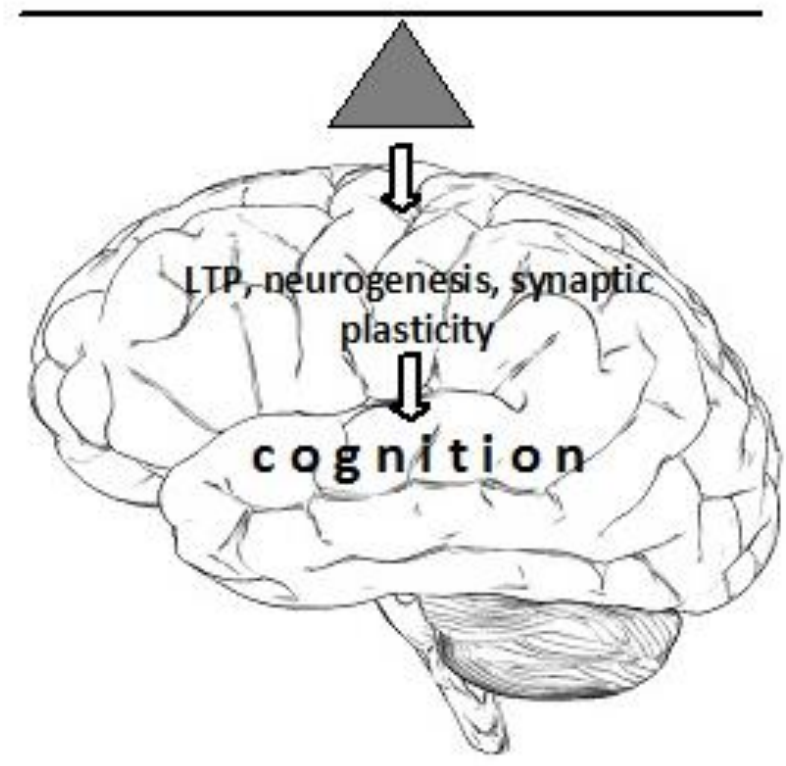

Figure 1. Cytokines and cognition

Clinical relevance/aspects of immunenervous system interactions for cognitive functioning in humans

Changes in cognitive processes become more frequent with aging. As regards to the immune system, studies have shown that senescence is associated with an exaggerated inflammatory response and a decrease in production of antiinflammatory proteins. Activation of the brain's resident immune cells - microglia can of normal neuro-immmune communications. IL-10 inhibits sickness behavior and contributes in reducing the negative effect of inflammation on hippocampal-dependent working memory (26). There are evidence that IL-10 possesses the potential to modulate early brain development and the consequent cognitive functioning $(27,28)$. Both IL-4 and IL-10 can abrogate learning and memory deficits observed in inflammatory models of Alzheimer's disease $(29,30)$

Taken together experimental data suggest that activation of cytokine network within physiological range is a necessary phenomenon for development and maintenance of normal cognitive functions (Figure 1).

\section{Anti-in flammatory cytokines}


the results of a cross-sectional study of Wright et al. 2006, about negative correlation between serum IL-6 and Mini Mental State Examination score (32). In agreement are data from several other investigations - Maastricht Aging Study, 2003; Memory and Morbidity in Augsburg Elderly (MEMO) Study, 2008; Health Aging and Body Composition (Health ABC) Study, 2009, supporting the association between increased risk of cognitive decline and high concentrations of inflammatory factors (33-35).

Studies, which explore the correlation between specific cognitive domain and different cytokines, give contradictory results. Elwan et al., 2003 have found association between high IL-6 serum levels and significant impairment in attention and sensory (intentional) memory (36). The same cytokine was shown to have negative correlation with the IQ in octogenarians (Krabbe, 2007), with executive functions (PROSPER study) and with the working memory in healthy senior individuals (37-39). On the opposite side are the results of Dik et al 2005 and Baune et al 2008, which did not confirm such relationship $(34,40)$.

Another body of evidence for the role of immune mechanisms in the cognitive functioning is provided by investigations of cognitive abilities during acute or chronic inflammatory states. The so called "sickness behavior" accompanied by transient decrease in attention and memory functions is a well known phenomenon in acute viral (e.g. inflienza) infections. A classical example in this area is the effect of endotoxin administration in healthy volunteers. Along with markedly increased circulating levels of IL-6, TNF-a, soluble TNF receptors, IL-1ra, and cortisol it has produced a global decrease in memory functions, reflected by decreased immediate recall of story items, reduced delayed story recall, a deficit in immediate and delayed recall of figure items, and decreased performance in Word List Learning, 1, 3 and 9 hours after intravenous injection. Impairments in immediate and delayed story recall have been found to correlate significantly and positively with the secretion of IL-6, TNFalpha, and IL-1ra (41).

In attempt to search for causality between cognitive impairment and cytokine concentrations Arnold et al., 2002, have examined short-term memory, selective attention, and executive control after administration of IL-6. Surprisingly, no cognitive disturbances but improvement in short-term memory has been observed (42).
TRENOVA A., et al. This study demonstrates again that the consequences of elevated IL-6 levels are determined by many factors. In consistence with this theory are the results from studies assessing memory functions in patients with autoimmune diseases. Higher levels of IL-6 in the serum were associated with higher learning scores in patients with systemic lupus erythematosus and with lower score on Mini Mental State Examination in patients with relapsing-remitting multiple sclerosis $(43,44)$.

Associations have been reported between immune biomarkers and aging-associated neurodegenerative diseases, particularly Alzheimer's disease (AD). Mononuclear cells from $\mathrm{AD}$ patients have shown higher basal pro-inflammatory cytokine production in vitro (45). A study conducted by Yang et al. 2009 has demonstrated significant correlation between increased serum TNF-alpha and the risk of developing the disease (46). Higher serum concentrations of IL-17, IL-18 and IL23 have been found in patients with $\mathrm{AD}$ compared to healthy controls (47). The immune activation in $\mathrm{AD}$ is also supported by the data for increased levels of IL-1beta; IL-6 and TNF-alpha in cerebro-spinal fluid of these patients and microglial activation with proinflammatory cytokine secretion in histological samples obtained by biopsy or post mortem (48, 49). Despite of the large amount of evidence for involvement of the immune system in neurodegenerative dementia its role as a causality factor or a consequence is still contentious. The other major question is whether inflammation in dementia must be therapeutically affected, in what direction and how.

\section{CONCLUSIONS}

This short review highlights the critical involvement of the immune system in different aspects of cognitive functioning. During normal, quiescent conditions, immune system positively regulates learning and memory via interactions among neurons, glia and other brain cells. Cytokine-induced modulation of memory processes is a complex phenomenon, including both detrimental and beneficial effects, depending on the specific cytokine, its levels within the brain, and the particular condition that changes the cytokine secretion. Although the knowledge in this field increased dramatically during the last decades there are still many unknown details about the intimate mechanisms underlying immune-cognitive interactions in humans. Attempts to correlate serum cytokine levels or their CSF and local concentrations with different cognitive domains represent serious challenges. Much more research is needed to establish the 
immune biomarkers indicating detrimental or protective effect on cognitive abilities in healthy individuals and in different pathological conditions and thus to allow development of more effective preventive and therapeutic strategies for cognitive boosting.

\section{REFERENCES}

1. Marin, I. and Kipnis, J., Learning and memory ... and the immune system. Learn Mem, 20(10):601-606, 2013.

2. Kipnis, J., Cohen, H., Cardon, M., Ziv, Y. and Schwartz, M., T cell deficiency leads to cognitive dysfunction: implications for therapeutic vaccination for schizophrenia and other psychiatric conditions. Proc Natl Acad Sci, 101:8180-8185, 2004.

3. Ron-Harel, N., Segev, Y., Lewitus, G.M., Cardon, M., Ziv, Y., Netanely, D., JacobHirsch, J., Amariglio, N., Rechavi, G., Domany, E. and Schwartz, M., Agedependent spatial memory loss can be partially restored by immune activation. Rejuvenation Res, 11:903-913, 2008.

4. Brynskikh, A., Warren, T., Zhu, J. and Kipnis, J., Adaptive immunity affects learning behavior in mice. Brain Behav Immun, 22: 861-869, 2008.

5. Ziv, Y., Ron, N., Butovsky, O., Landa, G., Sudai, E., Greenberg, N., Cohen, H., Kipnis, J. and Schwartz, M., Immune cells contribute to the maintenance of neurogenesis and spatial learning abilities in adulthood. Nat Neurosci, 9:268-275, 2006.

6. Ron-Harel, N. and Schwartz, M., Immune senescence and brain aging: can rejuvenation of immunity reverse memory loss? Trends Neurosci, 32:367-375, 2009.

7. Derecki, N.C., Cardani, A.N., Yang, C.H., Quinnies, K.M., Crihfield, A., Lynch, K.R. and Kipnis, J., Regulation of learning and memory by meningeal immunity: a key role for IL-4. J Exp Med, 207:1067-1080, 2010.

8. McAfoose, J. and Baune, B.T., Evidence for a cytokine model of cognitive function. Neurosci Biobehav Rev, 33:355-366, 2009.

9. Hryniewicz, A., Bialuk, I., Kamiński, K.A. and Winnicka, M.M., Impairment of recognition memory in interleukin-6 knockout mice. Eur J Pharmacol, 577:219-220, 2007.

10.Jankowsky, J.L., Derrick, B.E. and Patterson, P.H., Cytokine responses to LTP induction in the rat hippocampus: a comparison of in vitro and in vivo techniques. Learn Mem, 7:400-412, 2000.

11.Tancredi, V., D'Antuono, M., Cafè, C., Giovedì, S., Buè, M.C., D'Arcangelo, G., Onofri, F. and Benfenati, F., The inhibitory effects of interleukin-6 on synaptic
TRENOVA A., et al.

plasticity in the rat hippocampus are associated with an inhibition of mitogenactivated protein kinase ERK. $J$ Neurochem, 75:634-643, 2000.

12.Balschun, D., Wetzel, W., Del Rey, A., Pitossi, F., Schneider, H., Zuschratter, W. and Besedovsky, H.O., Interleukin-6: a cytokine to forget. FASEB $J, 18: 1788$ 1790, 2004.

13.Braida, D., Sacerdote, P., Panerai, A.E., Bianchi, M., Aloisi, A.M., Iosue, S. and Sala, M., Cognitive function in young and adult IL (interleukin)-6 deficient mice. Behav. Brain Res, 153:423-429, 2004.

14.Heyser, C.J., Masliah, E., Samimi, A., Campbell, I.L. and Gold, L.H., Progressive decline in avoidance learning paralleled by inflammatory neurodegeneration in transgenic mice expressing interleukin 6 in the brain. Proc Natl Acad Sci USA, 94:1500-1505, 1997.

15.Tha, K.K., Okuma, Y., Miyazaki, H., Murayama, T., Uehara, T., Hatakeyama, R., Hayashi, Y. and Nomura, Y., Changes in expressions of proinflammatory cytokines IL-1beta, TNF-alpha and IL-6 in the brain of senescence accelerated mouse (SAM) P8. Brain Res, 885:25-31, 2000.

16. Yirmiya, R. and Goshen, I., Immune modulation of learning, memory, neural plasticity and neurogenesis. Brain Behav Immun, 25:181-213, 2011.

17.Cumiskey, D., Pickering, M. and O'Connor, J.J., Interleukin-18 mediated inhibition of LTP in the rat dentate gyrus is attenuated in the presence of mGluR antagonists. Neurosci Lett, 412:206-210, 2007.

18.Baron, R., Nemirovsky, A., Harpaz, I., Cohen, H., Owens, T. and Monsonego, A., IFN-gamma enhances neurogenesis in wildtype mice and in a mouse model of Alzheimer's disease. FASEB $J, 22: 2843-$ 2852, 2008.

19.Baune, B.T., Wiede, F., Braun, A., Golledge, J., Arolt, V. and Koerner, H., Cognitive dysfunction in mice deficient for TNF and its receptors. Am J Med Genet B Neuropsychiatr Genet, 147:1056-1064, 2008.

20.Aloe, L., Properzi, F., Probert, L., Akassoglou, K., Kassiotis, G., Micera, A. and Fiore, M., Learning abilities, NGF and BDNF brain levels in two lines of TNFalpha transgenic mice, one characterized by neurological disorders, the other phenotypically normal. Brain Res, 840:125-137, 1999.

21.Fiore, M., Angelucci, F., Alleva, E., Branchi, I., Probert, L. and Aloe, L., Learning performances, brain NGF distribution and NPY levels in transgenic 
mice expressing TNF-alpha. Behav Brain Res, 112:165-175, 2000.

22.Golan, H., Levav, T., Mendelsohn, A. and Huleihel, M., Involvement of tumor necrosis factor alpha in hippocampal development and function. Cereb Cortex, 14:97-105, 2004.

23.Gerber, J., Bottcher, T., Hahn, M., Siemer, A., Bunkowski, S. and Nau, R., Increased mortality and spatial memory deficits in TNF-alpha-deficient mice in ceftriaxonetreated experimental pneumococcal meningitis. Neurobiol Dis, 16:133-138, 2004.

24.Wilson, C.J., Finch, C.E. and Cohen, H.J., Cytokines and cognition--the case for a head-to-toe inflammatory paradigm. $J \mathrm{Am}$ Geriatr Soc, 50(12):2041-2056, 2002.

25.Gadani, S.P., Cronk, J.C., Norris, G.T. and Kipnis, J., IL-4 in the brain: a cytokine to remember. J Immunol, 189(9):4213-4219, 2012.

26.Richwine, A.F., Sparkman, N.L., Dilger, R.N., Buchanan, J.B. and Johnson, R.W., Cognitive deficits in interleukin-10deficient mice after peripheral injection of lipopolysaccharide. Brain Behav Immun, 23(6):794-802, 2009.

27.Meyer, U., Nyffeler, M., Engler, A., Urwyler, A., Schedlowski, M., Knuesel, I., Yee, B.K. and Feldon, J., The time of prenatal immune challenge determines the specificity of inflammation-mediated brain and behavioral pathology. J Neurosci, 26(18):4752-4762, 2006.

28.Meyer, U., Murray, P.J., Urwyler, A., Yee, B.K., Schedlowski, M. and Feldon, J., Adult behavioral and pharmacological dysfunctions following disruption of the fetal brain balance between proinflammatory and IL-10-mediated antiinflammatory signaling. Mol Psychiatry, 13(2):208-221, 2008.

29.Kawahara, K., Suenobu, M., Yoshida, A., Koga, K., Hyodo, A., Ohtsuka, H., Kuniyasu, A., Tamamaki, N., Sugimoto, Y. and Nakayama, H., Intracerebral microinjection of interleukin-4/interleukin13 reduces $\beta$-amyloid accumulation in the ipsilateral side and improves cognitive deficits in young amyloid precursor protein 23 mice. Neuroscience, 207:243-260, 2012.

30.Kiyota, T., Ingraham, K.L., Swan, R.J., Jacobsen, M.T., Andrews, S.J. and Ikezu, T., AAV serotype 2/1-mediated gene delivery of anti-inflammatory interleukin10 enhances neurogenesis and cognitive function in APP+PS1 mice. Gene Therapy, 19(7):724-733, 2012.

31.Yaffe, K., Lindquist, K., Penninx, B.W., Simonsick, E.M., Pahor, M., Kritchevsky,
TRENOVA A., et al. S. and Harris, T., Inflammatory markers and cognition in well-functioning AfricanAmerican and white elders. Neurology, 61:76-80, 2003.

32.Wright, C.B., Sacco, R.L., Rundek, T.R., Delman, J.B., Rabbani, L.E. and Elkind, M.S.V., Interleukin-6 is associated with cognitive function: The Northern Manhattan Study. J Stroke Cerebrovasc Dis, 15:34-38, 2006.

33.Teunissen, C.E., van Boxtel, M.P.J., Bosma, H., Bosmans, E., Delanghe, J., De Bruijn, C. and de Vente, J., Inflammation markers in relation to cognition in a healthy aging population. $J$ Neuroimmunol, 134:142-150, 2003.

34.Baune, B.T., Ponath, G., Golledge, J., Varga, G., Arolt, V., Rothermundt, M. and Berger, K., Association between IL-8 cytokine and cognitive performance in an elderly general population - The MEMOStudy. Neurobiology of Aging, 29:937-944, 2008.

35.Yaffe, K., Fiocco, A.J., Lindquist, K., Vittinghoff, E., Simonsick, E.M., Newman, A.B. and Harris, T.B., Predictors of maintaining cognitive function in older adults: The Health ABC Study. Neurology, 72:2029-2035, 2009.

36.Elwan, O., Madkour, O., Elwan, F., Mostafa, M., Abbas Helmy, A., AbdelNaseer, M., Abdel Shafy, S. and El Faiuomy, N., Brain aging in normal Egyptians: cognition, education, personality, genetic and immunological study. J Neurol Sci,211(1-2):15-22, 2003.

37.Krabbe, K.S., Mortensen, E.L., Avlund, K., Pilegaard, H., Christiansen, L., Pedersen, A.N., Schroll, M., Jørgensen, T., Pedersen, B.K. and Bruunsgaard, H., Genetic priming of a proinflammatory profile predicts low IQ in octogenarians. Neurobiol Aging, 30(5):769-781, 2009.

38.Mooijaart, S.P., Sattar, N., Trompet, S., Lucke, J., Stott, D.J., Ford, I., Jukema, J.W., Westendorp, R.G., de Craen, A.J. and PROSPER Study Group., Circulating interleukin-6 concentration and cognitive decline in old age: the PROSPER study. $J$ Intern Med, 274(1):77-85, 2013.

39.Simpson, E.E., Hodkinson, C.F., Maylor, E.A., McCormack, J.M., Rae, G., Strain, S., Alexander, H.D. and Wallace, J.M., Intracellular cytokine production and cognition in healthy older adults. Psychoneuroendocrinology, 38(10):2196208, 2013.

40.Dik, M.G., Jonker, C., Hack, C.E., Smit, J.H., Comijs, H.C. and Eikelenboom, P., Serum inflammatory proteins and cognitive 
TRENOVA A., et al.

decline in older persons. Neurology, 64(8):1371-1377, 2005.

41.Reichenberg, A., Yirmiya, R., Schuld, A., Kraus, T., Haack, M., Morag, A. and Pollmacher, T., Cytokine-associated emotional and cognitive disturbances in humans. Arch Gen Psychiatry, 58:445-452, 2001.

42.Arnold, M.C., Papanicolaou, D.A., O'Grady, J.A., Lotsikas, A., Dale, J.K., Straus, S.E. and Grafman, J., Using an interleukin-6 challenge to evaluate neuropsychological performance in chronic fatigue syndrome. Psychol Med, 32(6):1075-1089, 2002.

43.Kozora, E., Laudenslager, M., Lemieux, A., and West, S. G., Inflammatory and hormonal measures predict neuropsychological functioning in systemic lupus erythematosus and rheumatoid arthritis patients. J Int Neuropsychol Soc, 7(6):745-754, 2001.

44.Patanella, A.K., Zinno, M., Quaranta, D., Nociti, V., Frisullo, G., Gainotti, G., Tonali, P.A., Batocchi, A.P. and Marra, C., Correlations between peripheral blood mononuclear cell production of BDNF, TNF-alpha, IL-6, IL-10 and cognitive performances in multiple sclerosis patients. J Neurosci Res, 88(5):1106-1112, 2010.

45.Rocha, N.P., Teixeira, A.L., Coelho, F.M., Caramelli, P., Guimarães, H.C., Barbosa,
I.G., da Silva, T.A., Mukhamedyarov, M.A., Zefirov, A.L., Rizvanov, A.A., Kiyasov, A.P., Vieira, L.B., Janka, Z., Palotás, A. and Reis, H.J., Peripheral blood mono-nuclear cells derived from Alzheimer's disease patients show elevated baseline levels of secreted cytokines but resist stimulation with $\beta$-amyloid peptide. Mol Cell Neurosci, 49(1):77-84, 2012.

46. Yang, L., Lu, R., Jiang, L., Liu, Z. and Peng, Y., Expression and genetic analysis of tumor necrosis factor-alpha (TNF-alpha) G-308A polymorphism in sporadic Alzheimer's disease in a Southern China population. Brain Res, 1247:178-181, 2009.

47.Chen, J.M., Jiang, G.X., Li, Q.W., Zhou, Z.M. and Cheng, Q., Increased serum levels of interleukin-18, -23 and -17 in Chinese patients with Alzheimer's disease. Dement Geriatr Cogn Disord, 38(5-6):321-329, 2014.

48.Butchart, J. and Holmes, C., Systemic and central immunity in Alzheimer's disease: therapeutic implications. CNS Neurosci Ther, 18(1):64-76, 2012.

49.Liu, Y.H., Zeng, F., Wang, Y.R., Zhou, H.D., Giunta, B., Tan, J. and Wang, Y.J.,, Immunity and Alzheimer's disease: immunological perspectives on the development of novel therapies. Drug Discov Today 18(23-24):1212-1220, 2013. 